opinion I had the concurrence of my esteemed friends, $\mathrm{Mr}$. Henry Jackson of Sheffield and Staff-Surgeon Moore, to whom Ifeel very grateful for their unwearied attention and able assistance during the most trying part of this very interesting case.

Manchester, 1858 .

ON THE

\section{USE OF HYDROCHLORATE OF AMMONIA IN NEURALGIA.}

By HORATIO C. BRENCHLEY, Esq., M.R.C.S., SURGEON TO THI BRIGHTON DISPENSARY.

IN the " Clinical Records" of THE LANCET of the 2nd inst. were a few remarks on the use of the hydrochlorate of ammonia in neuralgia. Having been for a long time, until lately, a great sufferer from this complaint, I have marked down a few observations on the action of this remedy which have fallen under my immediate notice.

The hydrochlorate of ammonia, although a very old medicine, has been very rarely employed internally. I cannot call to mind having once seen it so used during the whole time I have been in the profession. It has, however, as you observe, been long in use in Germany, though chiefly as an alterative and resolvent; but, recently, it has been much in repute in India for the cure of neuralgia. I can bear testimony myself to its great value in this painful affection.

The method of exhibiting it is in doses of half a drachm, in camphor-mixture or spearmint-water, every hour during the paroxysm, until the pain is relieved; and it is affirmed, that the prolonged use of it, in smaller doses, for a few days, produces immunity from future attacks.

In order that I may not occupy too much of your time and space, I will relate but one case:-A young ma, aged twenty three, unmarried, healthy, and without any other apparent complaint, had long suffered from very severe attacks of neuralgia of the face, coming on at intervals of about one month, and lasting from two or three days to a week. It sometimes came on on one side of the face, and at other times on the other side. During one of these attacks I saw him, and ordered him quinine and arsenic, which put an end to the attack for the time. After the lapse of a month or six weeks, he had a second attack, which was cured in the same way. A third attack, however, came on after a shorter interval. This time the quinine and arsenic failed to relieve him. On the third day, when I saw him, he was in great agony, propped up in bed, and unable to do anything from the severity of the pain. The left side of his face was swollen, flushed, and hot, the temperature considerably higher than on the right side; the heat also of the inside of the mouth was so great, that I expected I should find matter forming from decayed teeth; but, on examination, I failed to do so.

I now tried the much-vaunted remedy-the valerianate of ammonia, but without any effect. The usual remedies having failed, I gave him the hydrochlorate of ammonia, in doses of half a drachm, every hour, in camphor-mixture. I saw him three hours after he had commenced this treatment, and found he had been much relieved after taking the second dose; and, having taken the third dose, he was almost free from pain, and begged to be allowed to continue the remedy. The heat and flushing of the face had subsided, and the temperature of the mouth considerably reduced, feeling quite cool after the burning heat of its former state. He went on for three or four days with the remedy, in doses of fifteen grains, three times a day, although there was no return of pain. Three months have now elapsed, and he bas had no relapse.

The modus operandi of this medicine is not very clear; but whatever other specific virtues it possesses for the cure of neu. ralgia, in this particular case it evidently acted as an indirect sedative, by lessening the arterial action; for the first and most striking effect of the medicine was the rapid lowering of the temperature of the mouth and face. From further observation I have found that this remedy is most useful in those cases of neuralgia which are attended with heat and swelling.

From what I have seen of its action, I shall, for the future, always feel that we have, in the hydrochlorate of ammonia, an addition to our list of remedies for neuralgia which is most nseful, safe, and efficient.

Lansdowne-place, Brighton, Oct, 1858

\section{6}

ON A CASE OF

\section{DISLOCATION OF THE ULNA AND RADIUS} BACKWARDS.

REDUCTION AFTER FIFTY-TWO DAYS.

BY W. PHILPOT BROOKES, M.D., F.R.C.S.

Sarah G-, aged seven years, fell down while at play in the yard of the workhouse, on the 15th of August, 1858, and met with what at that time was deemed an injury of the elbow-joint. On the 2nd of October, the surgeon of the house (who had been elected some days after the occurrence of the accident) called on me to examine the case. I immediately discovered the nature of the injury, and endeavoured by gentle manipulation to break down the adhesions, finding it useless at that time to endeavour to reduce the dislocation. We allowed the case to remain until Monday, Oct. 4th, intending on that day to give the child chloroform.

Oct. 4th. -I did not administer chloroform. I made exten. sion with my thumb in the axilla, grasping with my hand the humerus. With the other hand I made counter-extension from the wrist, and bending the elbow-joint round my knee. This was kept up some five minutes or more. One or twice during the time I found the adhesions give way, and shortly after. wards I felt the sudden jerk of reduction. She could now perform flexion, extension, pronation, and supination perfectly. The olecranon had returnnd to its natural situation. The con. dyles of the humerus were also now in their true position.

The length of time-fifty-two days-since the occurrence of the dislocation, gives this case, in a practical point, some interest, Boyer having laid it down that such a dislocation is rarely, if ever, reduced after the fifteenth day. I believe Sir Astley Cooper succeeded, in a like injury, after a longer time had elapsed than fifty-one days.

Cheltenham, Oet. 1858.

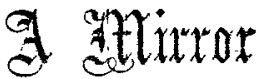

OF THE PRACTICE OF

\section{MEDICINE AND SURGERY IX THE}

\section{HOSPITALS OF LONDON.}

Nulka est alia pro certo noscendi via, nisi quam plurimas et morbornm et dissectionum historias, tam aliorum proprias, collectas habere et inter se com parare.-Mongagi. De Sed.et Caus. Morb.lib.14. Proamium.

\section{ST. MARY'S HOSPITAT.}

\section{DIAPHRAGMATIC HERNIA, WITH SYMPTOMS OF PNEUMO-} THORAX ;

THE STOMACH, SPLEEN, OMENTUM, AND TRANSVERSE COLON LYING IN THE LEIT PLEURA; FATAL RESULT.

(Under the care of Dr. ALDERSON.)

THE extreme interest which attaches to the subject of dis. placement of the thoracic viscera, especially to such an oecurrence as a diaphragmatic hernia-wherein the heart and lungs are compressed by the stomach and spleen-is so great, that were it not for the length of the following case, we should have devoted more space to its consideration. We glean from the history of the case that the patient had a severe fall two years ago, when, if the opening in the diaphragm were not congenital, the original rent may have taken place, and subsequently have become healed. In an elaborate account of this kind of hernia given by Nelaton, ${ }^{*}$ this point is alluded to in the following words: "When individuals have not succumbed to the immediate effects of a wound or tearing of the diaphragm, they recover, the tear or wonnd heals, and it is not until some future accident occurs that fatal mischief arises." On reference to the many recorded cases of congenital diaphragmatic hernia,

\footnotetext{
* Elemens de Pathologie Chirurgicale, tom. iv., 1857.
} 